\title{
Vitamin D Deficiency Reduces Vascular Reactivity of Coronary Arterioles in Male Rats
}

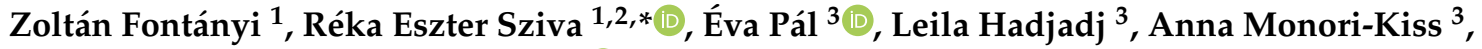 \\ Eszter Mária Horváth ${ }^{2}$, Rita Benkő ${ }^{2}{ }^{\circledR}$, Attila Magyar ${ }^{4}$, Andrea Heinzlmann ${ }^{5}$, Zoltán Benyó ${ }^{3}{ }^{\mathbb{D}}$, \\ György L. Nádasy ${ }^{2} \mathbb{D}$, Gabriella Masszi ${ }^{6, \dagger}$ and Szabolcs Várbíró ${ }^{1,+}$
}

1 Department of Obstetrics and Gynaecology, Semmelweis University,

Üllői Street 78/a, 1082 Budapest, Hungary; fontanyi.zoltan@med.semmelweis-univ.hu (Z.F.); varbiro.szabolcs@med.semmelweis-univ.hu (S.V.)

2 Department of Physiology, Semmelweis University, Túzoltó Street 37-47, 1094 Budapest, Hungary; horvath.eszter@med.semmelweis-univ.hu (E.M.H.); benko.rita@med.semmelweis-univ.hu (R.B.); nadasy.gyorgy@med.semmelweis-univ.hu (G.L.N.)

3 Department of Translational Medicine, Semmelweis University, Üllői Street 78/a, 1082 Budapest, Hungary; pal.eva@med.semmelweis-univ.hu (É.P.); leila.hadjadj@gmail.com (L.H.);

anna.monorikiss@gmail.com (A.M.-K.); benyo.zoltan@med.semmelweis-univ.hu (Z.B.)

4 Department of Anatomy, Histology and Embriology, Semmelweis University, Túzoltó Street 58, 1094 Budapest, Hungary; magyar.attila@med.semmelweis-univ.hu

5 Department of Anatomy and Histology, University of Veterinary Medicine, István Street 2, 1078 Budapest, Hungary; hmannandrea@gmail.com

6 Department of Internal Medicine, National Institute of Mental Health, Neurology and Neurosurgery, Lehel Street 59-61, 1135 Budapest, Hungary; gabriellamasszi@gmail.com

check for updates

Citation: Fontányi, Z.; Sziva, R.E.; Pál, É.; Hadjadj, L.; Monori-Kiss, A.; Horváth, E.M.; Benkő, R.; Magyar, A.; Heinzlmann, A.; Benyó, Z.; et al. Vitamin D Deficiency Reduces Vascular Reactivity of Coronary Arterioles in Male Rats. Curr. Issues Mol. Biol. 2021, 43, 79-92. https:// doi.org/10.3390/cimb43010007

Received: 4 April 2021

Accepted: 28 April 2021

Published: 7 May 2021

Publisher's Note: MDPI stays neutral with regard to jurisdictional claims in published maps and institutional affiliations.

Copyright: (c) 2021 by the authors. Licensee MDPI, Basel, Switzerland. This article is an open access article distributed under the terms and conditions of the Creative Commons Attribution (CC BY) license (https:// creativecommons.org/licenses/by/ $4.0 /)$.
* Correspondence: sziva.reka@semmelweis-univ.hu

+ These authors contributed equally to this work.

Abstract: Background: Vitamin D deficiency (VDD) may be considered an independent cardiovascular (CV) risk factor, and it is well known that CV risk is higher in males. Our goal was to investigate the pharmacological reactivity and receptor expression of intramural coronary artery segments of male rats in cases of different vitamin D supply. Methods: Four-week-old male Wistar rats were divided into a control group ( $n=11$ ) with optimal vitamin D supply (300 IU/ kgbw/day) and a VDD group ( $n=11,<0.5 \mathrm{IU} / \mathrm{kgbw} /$ day). After 8 weeks of treatment, intramural coronary artery segments were microprepared, their pharmacological reactivity was examined by in vitro microangiometry, and their receptor expression was investigated by immunohistochemistry. Results: Thromboxane $\mathrm{A}_{2}$ $\left(\mathrm{TXA}_{2}\right.$ )-agonist induced reduced vasoconstriction, testosterone $(\mathrm{T})$ and $17-\beta$-estradiol (E2) relaxations were significantly decreased, a significant decrease in thromboxane receptor (TP) expression was shown, and the reduction in estrogen receptor- $\alpha(E R \alpha)$ expression was on the border of significance in the VDD group. Conclusions: VD-deficient male coronary arteries showed deteriorated pharmacological reactivity to $\mathrm{TXA}_{2}$ and sexual steroids (E2, T). Insufficient vasoconstrictor capacity was accompanied by decreased TP receptor expression, and vasodilator impairments were mainly functional. The decrease in vasoconstrictor and vasodilator responses results in narrowed adaptational range of coronaries, causing inadequate coronary perfusion that might contribute to the increased CV risk in VDD.

Keywords: vitamin D deficiency; male; rat model; cardiovascular disease; pharmacological reactivity; thromboxane; estradiol; testosterone

\section{Introduction}

Several conflicting opinions exist on the link between vitamin D and cardiovascular diseases (CVDs). Although we still do not have any certain knowledge about the exact beneficial effect of vitamin D on CVDs, it seems that vitamin D deficiency (VDD) may be 
an independent cardiovascular risk factor associated with a higher risk of cardiovascular diseases, events, and mortality [1-3].

Vitamin D deficiency can be diagnosed when the serum 25-hydroxyvitamin D $(25(\mathrm{OH}) \mathrm{D})$ level is below $20 \mathrm{ng} / \mathrm{mL}$ (or $<50 \mathrm{nmol} / \mathrm{L}$ ) [4,5]. Based on this limit value, more than $40 \%$ of the world's population is vitamin D deficient [5]. Vitamin D exerts its effects on both nuclear and membrane vitamin D receptors (VDRn and VDRm); while VDRn belongs to the classical nuclear receptor family and is located in the nucleus, VDRm can be found on the cell surface, plasma membrane, and perinuclear area [6,7]. A vitamin-D-deficient state promotes not only endothelial dysfunction through influence on the structure and function of endothelial cells, but also vascular smooth muscle cell proliferation [8].

The sex difference in cardiovascular risk has been well-known since the Framingham Study [9-12]; men have relatively higher risk than women do, so reproductive-aged women are protected from these diseases. The most common cause of cardiovascular morbidity and mortality is coronary artery diseases (CADs) in both sexes, although the clinical appearance of the illnesses may differ [13]. In several acute CADs, such as myocardial infarction, angina pectoris, and sudden cardiac death, pro-thrombogenic factors (platelets and thromboxane $\mathrm{A}_{2}$ production) play an important role [14].

Thromboxane $\mathrm{A}_{2}\left(\mathrm{TXA}_{2}\right)$ is one of the main prostanoids that is generated not only by activated platelets but also by endothelial cells and vascular smooth muscle cells [15], synthetized by thromboxane-A synthase through the prostanoid pathway. TXA ${ }_{2}$ mediates paracrine and autocrine effects through its thromboxane $\mathrm{A}_{2}$ receptor $(\mathrm{TP}$, which is also available for other prostanoids [15]) and causes mainly platelet activation, degranulation, aggregation, and, in circulus vitiosus, further TXA $\mathrm{A}_{2}$ production. Besides this, it is an effective vasoconstrictor and plays a role in angiogenesis and inflammation [16]. TXA 2 binds to TP receptor, which is coupled to $\mathrm{G}$-protein $\left(\mathrm{G}_{\mathrm{q} / 11}\right.$ or $\left.\mathrm{G}_{12 / 13}\right)$ and activates phospholipase $\mathrm{C}$ (PLC); through this pathway, it finally increases the intracellular calcium concentration, which results in vasoconstriction [15]. With hydrolysis, $\mathrm{TXA}_{2}$ is converted quickly into thromboxane $\mathrm{B}_{2}\left(\mathrm{TXB}_{2}\right)$, a biologically inactive metabolite.

Sexual steroids have potential roles in cardiovascular sex-related variance; testosterone (T) and 17- $\beta$-estradiol (E2) are the two most potent sexual steroids ( $T$ in men and E2 in women), and both can cause genomic and rapid, non-genomic vasodilation via several different mechanisms and pathways, mostly in the appropriate sex [17,18].

Estrogens have two classical nuclear receptors, estrogen receptors $\alpha$ and $\beta(E R \alpha, E R \beta)$, and membrane-bound G-protein-coupled receptor 30 or G-protein-coupled estrogen receptor 1 (GPR30 or GPER1) $[17,19]$. By reducing endothelial dysfunction, causing vasodilation through a nitric oxide (NO)-mediated pathway, and decreasing vasoconstriction and vascular smooth muscle cell proliferation, estrogens have anti-hypertensive effects and play an important role in cardiovascular protection in women of reproductive age [17]. Estrogeninduced beneficial vascular responses are mainly mediated by endothelial ER $\alpha$ [20].

Androgens also have nuclear and 'membrane-bound or other' receptors. Besides the classical nuclear androgen receptor (AR), numerous receptors, signal transduction pathways, and ion channels have been investigated, which may have possible roles in androgen-induced vasodilation: the PLC, G-protein coupled receptor C6A (GPRC6A), oxoeicosanoid receptor 1 (OXER1), L dual oxidase 1 (DUOX1), Zinc transporter protein 9 (ZIP9), L-type voltage-dependent calcium-channel (LVDCC), voltage-dependent potassium channel $\left(\mathrm{K}_{\mathrm{v}}\right)$, small- and large-conductance calcium-activated potassium channels $\left(\mathrm{SK}_{\mathrm{Ca}}\right.$ $\left.\mathrm{BK}_{\mathrm{Ca}}\right)$, PI3K/Akt signaling pathway, modulation of cAMP and cGMP levels, mitochondrial procaspase 3 and $8, \mathrm{NADPH}$ oxidase, and transient receptor potential cation channel family members (TRPM8, TRPV4) [18,21]. Estrogens and androgens may affect platelet functions via the sex difference that was described in the effect of antithrombotic drugs [22].

However, the possible relationship of a vitamin-D-deficient state and pharmacological vascular responses of small vessels in the male sex is a less-researched area. Our aim was to investigate possible pharmacological reactivity changes of intramural resistance coronary artery segments in response to vasoconstrictor and several vasodilator agents in 
a vitamin-D-deficient state, and to further reveal the possible details and initial steps of increased cardiovascular risk in men.

\section{Materials and Methods}

\subsection{Animals}

Twenty-two 4-week-old, 100-140 g weighted male Wistar rats (Semmelweis University, Charles River, Budapest, Hungary) were involved in this 8-week-long experiment. Rats were housed $4-5$ together in a constant light-dark $(12: 12 \mathrm{~h})$ cycle and controlled temperature $\left(22 \pm 1{ }^{\circ} \mathrm{C}\right)$ and humidity $(56 \%)$ and were supplied with tap water and with normal or vitamin-D-deficient rat chow ad libitum.

\subsection{Treatment and Experimental Protocol}

Rats were distributed into two groups randomly, and we induced different vitamin D status in the animals as follows: From the first week, the control group $(n=11)$ received normal vitamin-D-containing conventional rat chow (containing $1000 \mathrm{IU} / \mathrm{kg}$ of vitamin D, SM Rat/mouse normal diet S8106-S011, Ssniff Spezialdiäten GmbH, Soest, Germany) constantly and vitamin D supplementation per os (Vigantol, $20.000 \mathrm{IU} / \mathrm{mL}$, Merck/Serono, Mumbai, India). Taken together, the daily vitamin D intake in the control group was approximately $300 \mathrm{IU} / \mathrm{kgbw}$, providing optimal vitamin D supply.

The vitamin-D-deficient group $(n=11)$ received $<0.5 \mathrm{IU} / \mathrm{kgbw} /$ day vitamin $\mathrm{D}$ for eight weeks to model vitamin D deficiency (VDD) status (rat chow containing <5 IU vitamin D, EF Rat/mouse VitD-free diet E15312-24, Ssniff Spezialdiäten GmbH, Soest, Germany; measured average daily chow intake: $0.1 \mathrm{~kg} / \mathrm{bwkg}$ chow). To validate our treatment protocol, serum 25-hydroxyvitamin D levels were measured from blood samples and found to be 5 times lower in the VDD group compared to control animals at the 8 th week of treatment, as our team published earlier [23]; this indicates the effectiveness of our treatment.

After 8 weeks, animals were sacrificed. Under general surgical anesthesia (Nembutal, $45 \mathrm{mg} / \mathrm{kg}$ b.w., i. p. Ceva-Phylaxia, Budapest, Hungary) and after perfusion via the carotid artery with heparinized Krebs-Ringer solution to wash out all blood from the vascular system, the chest was opened and the heart was removed, then the heart weights were measured. The intramural coronary arteriole was isolated (terminal branch of the left anterior descending/LAD coronary artery about in vivo 150-200 $\mu \mathrm{m}$ outer diameter at preparation) from the left ventricular muscle tissue under a stereomicroscope (Wild M3Z, Heerbrugg, Switzerland) [24]. Coronary arteriole segments with 150-200 micrometer outer diameter (length of about $2 \mathrm{~mm}$ ) were cut off for pressure microarteriography, and further sections of the arteries with surrounding ventricular tissue were cut off for immunohistochemical examinations.

\subsection{Pressure Microarteriography of Coronary Arterioles}

The excised coronary arteriole segments were placed into an organ chamber (Experimetria Ltd., Budapest, Hungary) filled with normal Krebs-Ringer solution (nKR), cannulated at both ends with microcannulas, and each was extended to its in vivo length. The composition of the $\mathrm{nKR}$ solution (in $\mathrm{mM} / \mathrm{L}$ ) was: $\mathrm{NaCl} 119 ; \mathrm{KCl} 4.7 ; \mathrm{NaH}_{2} \mathrm{PO}_{4} 1.2$; $\mathrm{MgSO}_{4}$ 1.17; $\mathrm{NaHCO}_{3} 24 ; \mathrm{CaCl}_{2}$ 2.5; glucose 5.5; and EDTA 0.034. The chamber was placed on the stage of a microscope (Leica, Wetzlar, Germany). Pressure-servo pumps (Living Systems, St. Albans Burlington, VT, USA) were connected to both cannulas, and the arterioles were pressurized to $50 \mathrm{mmHg}$ intraluminal pressure. The segments were allowed to equilibrate for $30 \mathrm{~min}$ at this pressure in nKR bubbled with a $5 \% \mathrm{CO}_{2}, 20 \% \mathrm{O}_{2}$, and $75 \% \mathrm{~N}_{2}$ gas mixture, and the temperature was kept at $37^{\circ} \mathrm{C}$ during the whole measurement period. After the arterioles were allowed to equilibrate at $50 \mathrm{mmHg}$ intraluminal pressure for $10 \mathrm{~min}$, cumulatively increasing concentrations of $17-\beta$-estradiol (Tocris Bio-Techne, Bristol, UK) were added to the chamber $\left(10^{-8}-10^{-5} \mathrm{~mol} / \mathrm{L}, 8 \mathrm{~min}\right.$ incubation for each step). After washing the segments with $\mathrm{nKR}$ and allowing them to equilibrate at $50 \mathrm{mmHg}$ 
intraluminal pressure for $10 \mathrm{~min}$, the segments were exposed to $10^{-8}$ and $10^{-6} \mathrm{~mol} / \mathrm{L}$ testosterone (Sigma-Aldrich, Darmstadt, Germany) with 5 min of incubation for both doses. Thereafter, with repeated washing with $\mathrm{nKR}$ and equilibration at $50 \mathrm{mmHg}$ intraluminal pressure for $10 \mathrm{~min}$, a cumulative dose-response curve with insulin (Actrapid penfill $100 \mathrm{IU} / \mathrm{mL}$, Novo Nordisk, Bagsværd, Denmark) was constructed (30, 100, 300, and $600 \mathrm{IU} / \mathrm{L}$ ). After $8 \mathrm{~min}$ incubation with each concentration, the vessel chamber was washed out and equilibrated at $50 \mathrm{mmHg}$ intraluminal pressure for $10 \mathrm{~min}$ with $\mathrm{nKR}$ again. Then, $10^{-6} \mathrm{~mol} / \mathrm{L}$ U46619, a stable thromboxane $\mathrm{A}_{2}$ receptor agonist, in a concentration causing maximal vasoconstriction (Tocris Bio-Techne, Bristol, UK) was administered. After this, the arterioles were allowed to equilibrate at $50 \mathrm{mmHg}$ intraluminal pressure for $10 \mathrm{~min}$. The endothelial relaxation capacity of arteriole segments was tested by cumulative application of adenosine (Adenocor, Sanofi-Aventis, Madrid, Spain) $\left(10^{-9}-10^{-6} \mathrm{~mol} / \mathrm{L}, 3 \mathrm{~min}\right.$ incubation for each step at $50 \mathrm{mmHg}$ intraluminal pressure). Finally, the fully relaxed diameter of vessels was measured in calcium-free Krebs solution; its composition was as follows (in $\mathrm{mM} / \mathrm{L}$ ): $\mathrm{NaCl}$ 92; $\mathrm{KCl} 4.7 ; \mathrm{NaH}_{2} \mathrm{PO}_{4} 1.18 ; \mathrm{MgCl}_{2} 20 ; \mathrm{MgSO}_{4}$ 1.17; $\mathrm{NaHCO}_{3} 24 ;$ glucose 5.5; EGTA 2; and EDTA 0.025. All compounds were purchased from Sigma-Aldrich (St. Louis, MO, USA). Pictures were taken during the measurement by a digital histological video camera (Leica DFC 320, Leica, Wetzlar, Germany) connected to the microscope. The outer and inner diameters $/ D_{o}$ and $D_{i}$ of the vessels were measured on the magnified pictures of the arterioles in ImageJ image analysis software (Image J 1.50b, National Institutes of Health, Bethesda, MD, USA). For the calibration, an Etalon micrometer (Wild, Heerbrugg, Switzerland) was used.

\subsection{Calculations}

From the inner and outer diameters, the following vessel characteristics were calculated:

- Inner radius $/ R_{i}(\mu \mathrm{m})$ :

$$
R_{\mathrm{i}}=\frac{D_{\mathrm{i}}}{2}
$$

- Outer radius $/ \mathrm{R}_{\mathrm{o}}(\mu \mathrm{m})$ :

$$
R_{\mathrm{o}}=\frac{D_{\mathrm{o}}}{2}
$$

- Myogenic tone (\%):

$$
\text { Myogenic tone }(\%)=\frac{R_{\mathrm{O}} \mathrm{Ca}-\text { free }-\mathrm{R}_{\mathrm{o} \mathrm{nKR}}}{\mathrm{R}_{\mathrm{o} \text { Ca }}-\text { free }} \times 100,
$$

- TXA $_{2}$-agonist-induced constriction (\%):

$$
\mathrm{TXA}_{2}-\text { constriction }(\%)=\frac{R_{\mathrm{O}} \mathrm{Ca}-\text { free }-\mathrm{R}_{\mathrm{o}} \mathrm{TXA} 2}{\mathrm{R}_{\mathrm{o}} \mathrm{Ca}-\text { free }} \times 100,
$$

- 17- $\beta$-estradiol-induced relaxation (\%):

$$
\mathrm{E} 2-\text { relaxation }(\%)=\frac{R_{\mathrm{o} \text { E2 }}-\mathrm{R}_{\mathrm{o} \text { nKR }}}{\mathrm{R}_{\mathrm{nKR}}} \times 100,
$$

- Testosterone-induced relaxation (\%):

$$
\mathrm{T}-\text { relaxation }(\%)=\frac{R_{\mathrm{o}} \mathrm{T}-\mathrm{R}_{\mathrm{o} \text { nKR }}}{\mathrm{R}_{\mathrm{o} \mathrm{nKR}}} \times 100,
$$

- Adenosine-induced relaxation (\%):

$$
\mathrm{ADE}-\text { relaxation }(\%)=\frac{R_{\mathrm{O}} \mathrm{ADE}-\mathrm{R}_{\mathrm{O} T \mathrm{TX} 2}}{\mathrm{R}_{\mathrm{O} \text { TXA2 }}} \times 100,
$$


- Insulin-induced relaxation (\%):

$$
\mathrm{INZ}-\text { relaxation }(\%)=\frac{R_{\mathrm{o} \text { INZ }}-\mathrm{R}_{\mathrm{o} \text { nKR }}}{\mathrm{R}_{\mathrm{o} \text { nKR }}} \times 100
$$

\subsection{Immunohistochemistry of Coronary Arterioles}

Coronary arteriole segments were freshly fixed with $4 \%$ formaldehyde. They were embedded in paraffin, sectioned, and mounted on a glass slide. Native sections were used for immunohistochemical (IHC) investigations. IHC stainings were performed against vitamin D receptor (VDR), endothelial nitric oxide synthase (eNOS), estrogen receptor$\alpha(\mathrm{ER} \alpha)$, thromboxane receptor (TP) and androgen receptor (AR). Mouse monoclonal anti-VDR (1:200, Santa Cruz Biotechnology, sc-13133, Dallas, TX, USA), anti-eNOS (1:50, Abcam, ab76198, Cambridge, UK) and rabbit polyclonal anti-ER $\alpha$ (1:100, Merck/SigmaAldrich, 06-935, St. Louis, MO, USA), anti-TP (1:50, MyBioSource, MBS2032166, San Diego, CA, USA), and anti-AR (1:100, Abcam, ab74272, Cambridge, UK) antibodies were applied. Secondary labeling was achieved by using a horseradish peroxidase (HRP)-labeled horse anti-rabbit and anti-mouse IgG polymer detection kit (Vector Laboratories, MP-7401, MP-7402, Burlingame, CA, USA, 30-40 min). A brown-colored 3-3'-diamino-benzidine peroxidase HRP substrate kit (Vector Laboratories, SK-4100, Burlingame, CA, USA) was used to visualize the specific antigen labeling, and blue-colored Hematoxylin QS nucleus stain (Vector Laboratories, H-3404-100, Burlingame, CA, USA) was used as counterstaining.

The immunostained sections were photographed with a microscope-coupled video camera (Zeiss Axio Imager.A1 with Zeiss AxioCam MRc5 CCD, Carl Zeiss, Jena, Germany or Nikon Eclipse Ni-U, 933584 with Nikon DS-Ri2 camera and NIS Elements BR image software, Nikon Corporation, Tokio, Japan). The area percentages of different parts of the vessel wall (tunica intima, media, or whole part) were measured from the digitized pictures using ImageJ image analysis software.

\subsection{Statistical Analysis}

Statistical analysis was performed with the help of GraphPad Prism 7.0 (GraphPad Software, San Diego, CA, USA) statistical software. After checking the KolmogorovSmirnov, D'Agostino and Pearson omnibus, and Shapiro-Wilk normality tests, in case of data with a normal distribution, we used the parametric unpaired T-test with F-test; data with a non-normal distribution were analyzed using the non-parametric Mann-Whitney U-test. Repeated-measures variance analysis (ANOVA) with Bonferroni's post hoc test was used in case of pharmaceutical agent doses. Because of the few applied doses, we decided to present our results in dose-response curves instead of nonlinear regression. For all statistical analyses, $p<0.05$ was considered statistically significant. All values are expressed as the Mean \pm SEM or Median [IQR]. Significance symbols: $*: p<0.05 ;{ }^{* *}: p<0.01$.

\section{Results}

\subsection{Heart Weight}

As our workgroup published previously, physiological, hormonal, and glucose-metabolism parameters; systolic and diastolic blood pressures; and the body weight of the rats measured did not differ between the two groups at the end of the experiment [23,25]. There was no significant difference between heart weights either (in Mean \pm SEM: $1.41 \pm 0.051 \mathrm{~g}$ and $1.55 \pm 0.048 \mathrm{~g}$ for the control and VDD groups, respectively, n.s.), indicating that the vitamin-D-deficient diet, at least within 8 weeks, did not affect this cardiovascular parameter.

\subsection{Coronary Arteriole Morphology and Function}

Significant differences were observed in inner radii: the VDD group had significantly lower inner radius than the control group $(p<0.01)$. In contrast, the outer radii of the coronary arteriole segments measured in passive circumstances seemed to be smaller but this difference did not reach the level of statistical significance in the two groups; the same was the case for the myogenic tone (Table 1, Figure 1). 
Table 1. Morphological and functional parameters of coronary arterioles. Inner and outer radii were measured in calcium-free solution; myogenic tone was calculated as described below for $50 \mathrm{mmHg}$ intraluminal pressure. Unpaired T-test or Mann-Whitney U-test. Data are expressed as Mean \pm SEM or Median [IQR], ${ }^{1} n=8-8$ and $^{2} n=6-6$ in each group, ${ }^{* *}: p<0.01$.

\begin{tabular}{ccc}
\hline Parameters/Groups & Control & VDD \\
\hline Inner radii $(\mu \mathrm{m})^{1}:$ & $89.06 \pm 5.23$ & $61.17 \pm 5.81^{* *}$ \\
${\text { Outer radii }(\mu \mathrm{m})^{1}:}^{*}$ & $131.6 \pm 8.49$ & $108.3 \pm 7.55$ \\
Myogenic tone $(\%)^{2}:$ & $5.14[1.30-18.41]$ & $2.44[1.36-4.18]$ \\
\hline
\end{tabular}

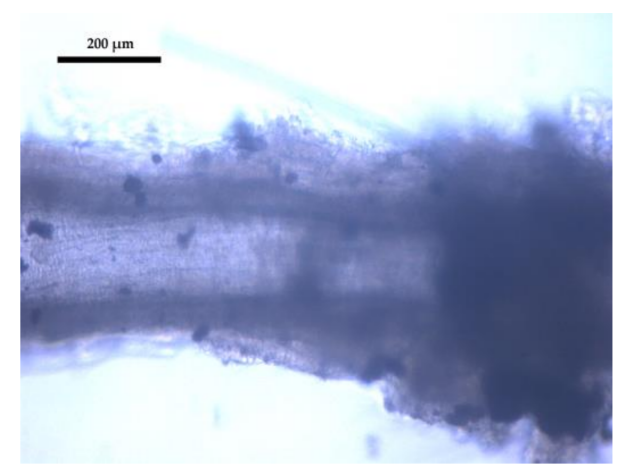

(a)

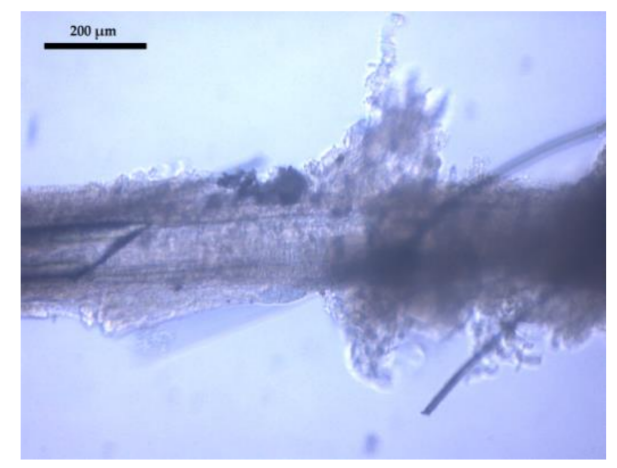

(b)

Figure 1. Representative images of intramural coronary artery segments from the control (a) and vitamin-D-deficient (b) groups in normal Krebs-Ringer solution at $50 \mathrm{mmHg}$ intraluminal pressure. Scale bar: $200 \mu \mathrm{m}$.

\subsection{Constriction Capacity of Coronary Arterioles: Thromboxane- $A_{2}$-Induced Contraction}

Thromboxane- $\mathrm{A}_{2}$-induced contraction was significantly $(p<0.05)$ decreased in the VDD group compared to the control group (Figure 2).

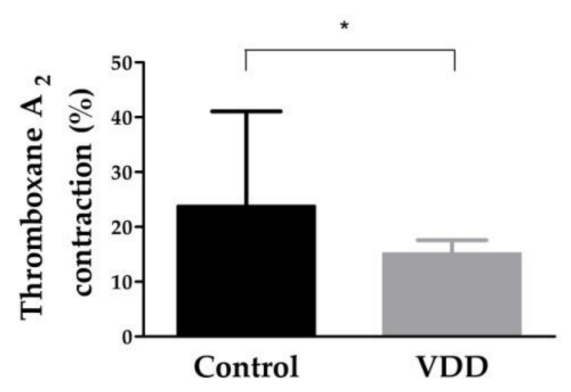

Figure 2. Thromboxane- $\mathrm{A}_{2}$-induced contraction of coronary arterioles. $(n=7-7)$ Calculated data are presented for $50 \mathrm{mmHg}$ intraluminal pressure. Mann-Whitney $\mathrm{U}$ test, Median [IQR], * $p<0.05$.

3.4. Relaxation Ability of Coronary Arterioles: 17- $\beta$-Estradiol-, Testosterone-, Adenosine-, and Insulin-Induced Relaxation

While the control group relaxed in response to $17-\beta$-estradiol, the vitamin-D-deficient group showed significantly lower relaxation $(p<0.05$ and $p<0.01)$ and mild contraction at higher doses (Figure 3a). 


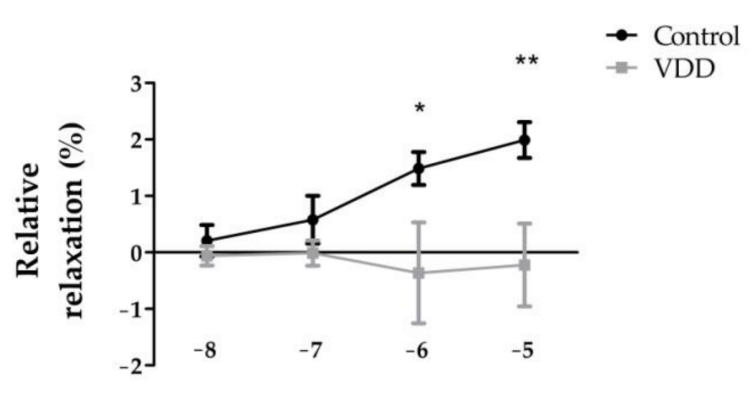

17- $\beta$-estradiol concentration (Log mol/l)

(a)

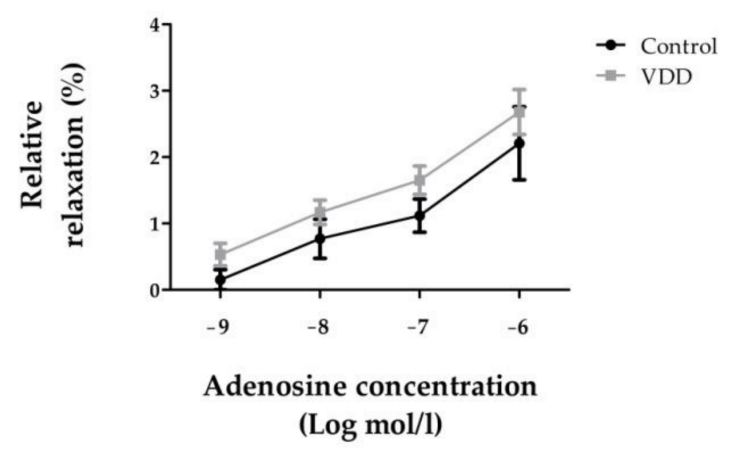

(c)

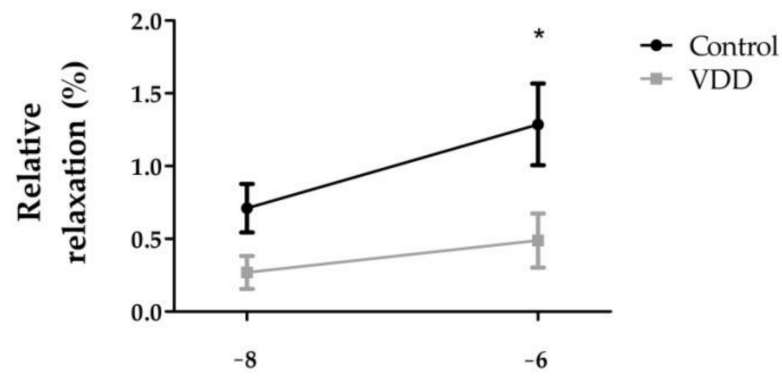

Testosterone concentration (Log mol/1)

(b)

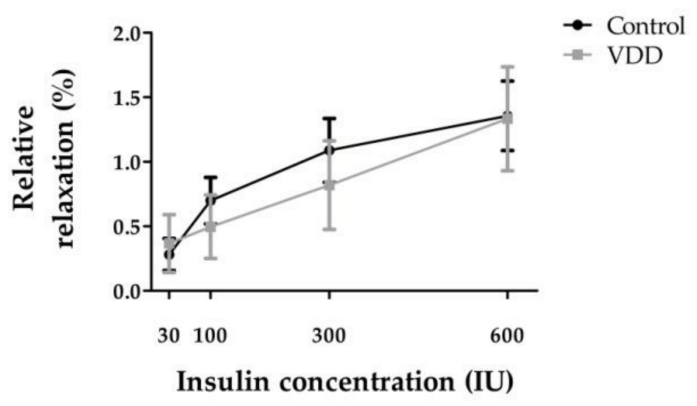

(d)

Figure 3. Relaxations of coronary arterioles induced by the administration of $17-\beta$-estradiol $((\mathbf{a}) ; \%, n=10-9)$, testosterone $((\mathbf{b}) ; \%, n=10-8)$, and adenosine $((\mathbf{c}) ; \%, n=8-10)$ in normal Krebs-Ringer solution in the presence of U46619 TXA2agonist at $50 \mathrm{mmHg}$ intraluminal pressure, and insulin-induced relaxation ((d); \%, $n=8-7)$ in normal Krebs-Ringer solution. Repeated-measures ANOVA, Bonferroni. Mean \pm SEM, ${ }^{*}: p<0.05 ;{ }^{* *}: p<0.01$.

Testosterone-induced vasodilation was significantly lower $(p<0.05)$ in the VDD group than in the control group (Figure 3b).

Adenosine-induced relaxation that was measured after thromboxane- $\mathrm{A}_{2}$-agonist contraction did not differ between the two groups (Figure 3c).

Insulin vasodilation was similar in both groups, though there were some variations between the shapes of the curves (Figure 3d).

\subsection{Immunohistochemical Stainings: $T P, E R \alpha, A R, e N O S$, and VDR}

Thromboxane receptor (TP) expression was significantly reduced in the vitamin-Ddeficient group, which is consistent with the result of decreased TXA 2 -induced vasoconstriction in this group (Figure $4 a, b$ ).

The estrogen-receptor- $\alpha$ expression was lower in the endothelial layer of the VDD group's coronary arteriole segments; the difference was on the border of statistical significance $(p=0.0571)$ (Figure 5a,b).

The androgen receptor expression showed no difference between the control and vitamin-D-deficient groups (positively stained endothelial area\%: 28.33 [12.06-56.03] and 23.40 [9.146-32.07] for the control and VDD groups, respectively, n.s.).

The investigation of endothelial NO-synthase expression showed that the vitamin-Ddeficient diet did not affect the expression of that enzyme in the intimal layer of the vessels (positively stained endothelial area\%: 13.87 [10.30-33.28] and 15.48 [7.10-20.94] for the control and VDD groups, respectively, n.s.).

There was also no difference in vitamin $\mathrm{D}$ receptor expression between the groups (positively stained whole vessel area\%: 23.25 [14.90-29.69] and 26.18 [17.64-37.68] for the control and VDD groups, respectively, n.s.). 


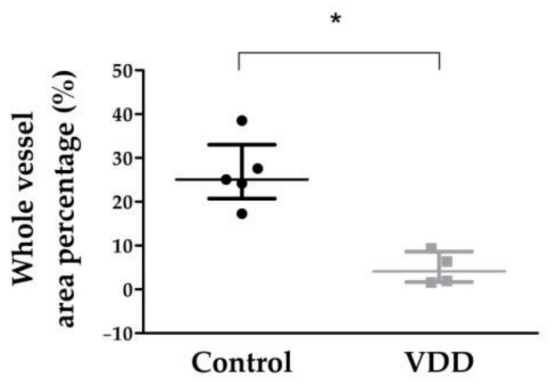

(a)
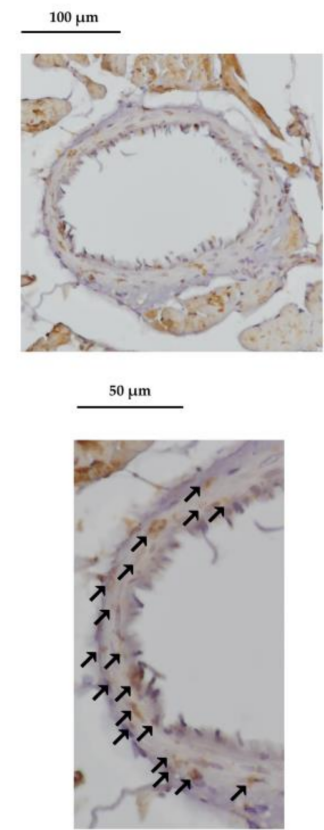

Control
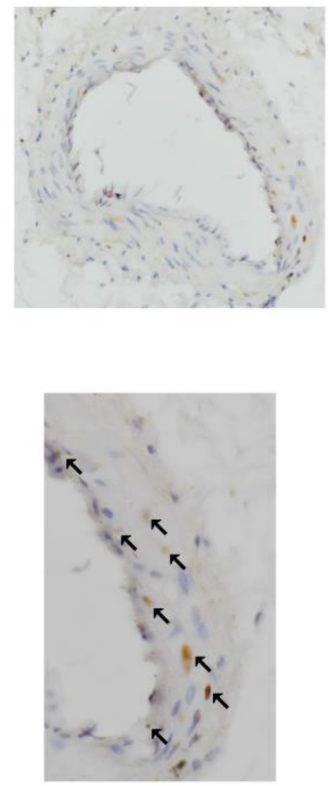

VDD

(b)

Figure 4. Results of thromboxane receptor immunohistochemical staining. (a) Percentage of the coronary arteriole crosssectional area positively stained with anti-TP antibodies. Mann-Whitney U-test. Median [IQR], $n=5-4 .{ }^{*}: p<0.05$; (b) Representative images of anti-TP-stained tissue sections of male rat coronary arteriole segments. Brown color indicates the TP-positive areas in both groups: in the control group, the whole vessel (endothelium and vascular smooth muscle cells) was stained, as well as the surrounding ventricular tissue, while in the VDD group, the brown color is much less pronounced. Scale bars: 100 and $50 \mu \mathrm{m}$. Black arrows indicate positively stained cells.

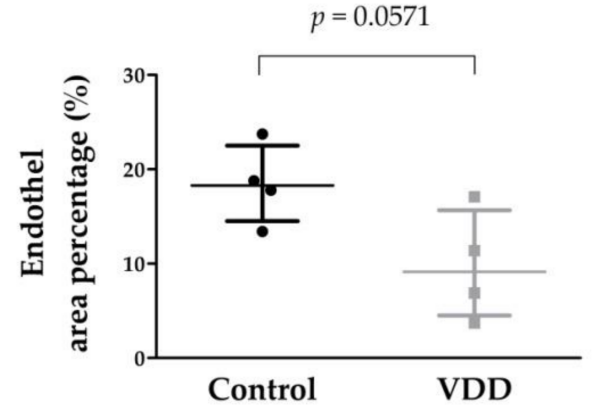

(a)
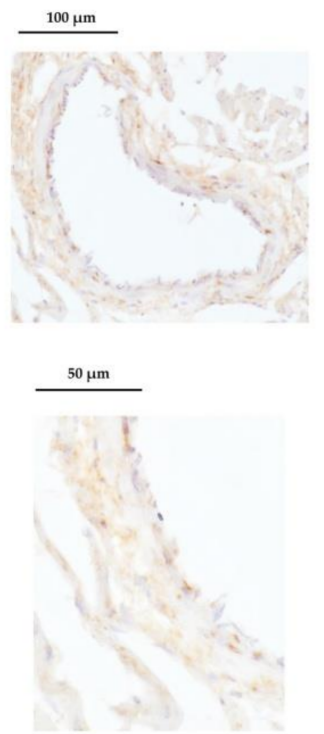

Control
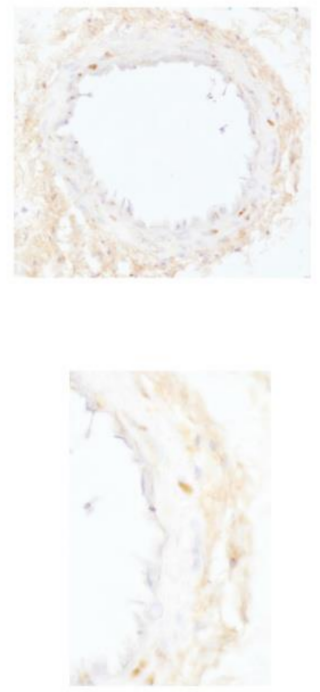

VDD

(b)

Figure 5. Results of anti-estrogen-receptor- $\alpha$ immunohistochemical staining. (a) Percentage of the coronary arteriole cross-sectional endothelial area positively stained with anti-ER $\alpha$ antibodies. Mann-Whitney U-test. Median [IQR], $n=4-4$. $p=0.0571$; (b) Representative images of anti-ER $\alpha$-stained tissue sections of male rat coronary arteriole segments. Brown color indicates the ER $\alpha$-positive areas in both groups: ER $\alpha$ expression is similar in the tunica media layer; however, in the VDD group the staining intensity of the endothelium is less visible. Scale bars, 100 and $50 \mu \mathrm{m}$. 


\section{Discussion}

To our knowledge, this is the first study finding significant alterations in the reaction of small intramural coronary arteriole segments to a vasoconstrictor and sexual steroids (estrogen and androgen) due to a vitamin-D-deficient state. Moreover, a part of the identified damages appeared at the molecular level, and the results of receptor expression examinations are in accordance with the identified pharmacological vasoreactivity impairments. Our main findings are that a vitamin-D-deficient state caused reduced inner radii, decreased thromboxane $\mathrm{A}_{2}$ agonist vasoconstriction, reduced thromboxane receptor expression, and diminished 17- $\beta$-estradiol and testosterone vasodilator capacity of the intramural coronary artery of male rats.

Reduced inner radii with unchanged outer radii may indicate vessel wall reorganization causing lumen narrowing, while the myogenic tone of the arteriole segments was not affected. Our workgroup detected inward eutrophic remodeling that can be considered as pre-hypertensive alteration in these small coronary arterioles in response to vitamin $\mathrm{D}$ deficiency [25].

Vasoconstrictor capacity, investigated by assessing thromboxane $\mathrm{A}_{2}$ agonist, significantly decreased in the coronary arteries of vitamin-D-deficient male rats, as did the expression of thromboxane $\mathrm{A}_{2}$ receptor (TP). Sex difference in thromboxane response has previously been observed: isolated coronary arteriole segments' $\mathrm{TXA}_{2}$-induced constriction was found to be significantly higher in male than in female animals [26]. Vitamin $\mathrm{D}$ may have a regulatory role in prostanoid pathways. The active form of vitamin $\mathrm{D}$ (1,25-dihidroxyvitamin D or 1,25(OH $\left.)_{2} \mathrm{D}\right)$ significantly decreased the cyclooxigenase-2 mRNA and protein expression and caused a significant dose-dependent increase in the prostaglandin-catabolizing 15-hydroxyprostaglandin dehydrogenase enzyme expression. Furthermore, vitamin D significantly reduced prostaglandin E2 $\left(\mathrm{PGE}_{2}\right)$ secretion and repressed $\mathrm{PGE}_{2}$ receptor isoform, EP2, and prostaglandin $\mathrm{F}_{2 \alpha}$ receptor FP expression in human prostate cancer and prostatic epithelial cell lines [27-29]. In an endotoxin shock male mouse model, 1- $\alpha$-hydroxyvitamin $\mathrm{D}, 1,25(\mathrm{OH})_{2} \mathrm{D}$, and 24,25-dihydroxyvitamin $\mathrm{D}$ reduced the plasma $\mathrm{TXB}_{2}$ levels, suggesting a role of vitamin $\mathrm{D}$ in thromboxane $\mathrm{A}_{2}$ production [30]. On the contrary, aortic rings of $1,25(\mathrm{OH})_{2}$ D-treated spontaneously hypertensive (SH) and Wistar-Kyoto (WKY) rats showed no difference in U46619-induced vasoconstriction and in thromboxane synthase gene and protein expression [31]; additionally, exogenous $1,25(\mathrm{OH})_{2} \mathrm{D}$ administration to isolated, de-endothelized aortic rings from SH and WKY rats did not cause a change in U46619-induced endothelium-independent contraction [32]. A human study found that after cardioplegia/reperfusion, the human coronary microvasculature showed significantly decreased $\mathrm{TXA}_{2}$-induced vasoconstriction compared to that before procedures, while the protein level and gene expression of thromboxane synthase and thromboxane $\mathrm{A}_{2}$ receptor did not differ in atrial tissue [33]. Vitamin-D-deficient pregnant female Wistar rats had higher placental mRNA levels and lower protein levels of phospholipase A2 and cyclooxigenase- 2 compared to the control group, while serum thromboxane $B_{2}$ levels were similar between the groups [34]. Moreover, the VDD group had higher liver and plasma arachidonic acid levels than the control one [35]. Similar results to ours were found in the coronary arterioles of vitamin-D-deficient female animals, $\mathrm{TXA}_{2}$ tone massively reduced in both VDD groups independently of their testosterone treatment [36]. Currently, our knowledge is inadequate about the possible link between vitamin $\mathrm{D}$, vitamin $\mathrm{D}$ deficiency, and thromboxane $\mathrm{A}_{2}$ in the male sex; this needs further detailed investigations.

Considering the relaxation capacities of the coronary arteriole segments from vitamin$D$-deficient male animals, $17-\beta$-estradiol- and testosterone-induced vasodilation showed a significant reduction, while relaxation in response to insulin and adenosine showed no difference compared to the control group. Testosterone administration produced significant dose-dependent vasorelaxation on the intrinsic tone of male Wistar rats' left and right coronary artery segments [37]. In the cerebral arteries of vitamin-D-deficient male rats, significantly enhanced testosterone-induced tone (opposite calculation to relaxation) and 
reduced AR expression were observed [38], which may indicate that vitamin D deficiency affects the receptor expression of distinct vascular regions differently. It is likely that nuclear and membrane receptor activation, effects on the vascular endothelium, and ion channel activation or inhibition may contribute to the rapid, non-genomic androgen-induced relaxation. The following hypothesis may explain our results: the altered testosterone-induced relaxation and still unchanged nuclear AR expression may suggest the involvement of 'membrane-bound or other' receptors, signal transduction pathways, and ion channels in the identified functional damage. Additionally, it is probable that both endotheliumdependent and endothelium-independent, direct vascular smooth muscle cell activation pathways are present [18], but the exact mechanisms and the detailed cardiovascular effects of androgens are still unclear.

In the male sex, the main sexual steroids are naturally the androgens. Thus, this could be a reason why in our experiment, in response to vitamin D deficiency, the estrogeninduced relaxation was altered first and was accompanied by initial changes in estrogen receptor- $\alpha$ expression. 17- $\beta$-estradiol-induced relaxation on perfused isolated hearts was significantly lower in male normotensive, control Wistar rats compared to female ones [39]; this sex difference could not be observed in spontaneous hypertensive animals [40], and orchiectomy caused a significant decrease in the E2 relaxation response of males compared to that in ovariectomized female animals [41], although castration did not damage this response fully.

One of the most important functions of endothelial NO-synthase (eNOS) is developing endothelium-dependent relaxation through $\mathrm{NO}$ production [42], and both estrogens and androgens play a role in this NO-mediated vasodilator pathway $[17,21]$. In our experiment, eNOS expression did not show any difference between the groups, which may indicate the deterioration of other, vascular-endothelium- and NO-independent relaxation pathways of sexual steroids due to vitamin $\mathrm{D}$ deficiency.

According to our results, in the male sex, vitamin D deficiency may induce alteration first in the vasoconstrictor characteristics of coronary arteries, because both functional and molecular changes developed clearly, while in terms of vasodilator reactivity, sexualsteroid-related impairments appeared mostly in vessel functionality. Other vasodilator pathways, such as adenosine, the most important vasodilator for coronary arteries, and insulin, were not yet affected. It seems that androgen-vitamin D effects in males are less connected than estrogen-vitamin D actions in females in association with carbohydrateinsulin metabolism. It has been proven that insulin relaxation is not altered in male coronary vessels due to vitamin $\mathrm{D}$ deficiency, while in vitamin-D-deficient females, insulin-induced relaxation is significantly decreased both in small coronary segments and in large, aortic rings $[43,44]$.

The association of vitamin D levels with cardiovascular diseases has been widely investigated [1,45]. Vitamin D receptors (VDRs) are expressed in endothelial and vascular smooth muscle cells of the vasculature [46], and vitamin D may play a role in the regulation of endothelial functions [47]. Vitamin D deficiency can be associated with endothelial dysfunction [46] and may have sex differences. In a human clinical cross-sectional study, the endothelial function of elderly (and, according to the data, vitamin-D-insufficient) individuals was investigated, and in women, but not in men, vitamin D levels were significantly associated with endothelium-independent vasodilation [48].

During our experiment, VDR expression was similar in the control and vitamin-Ddeficient groups. A significant elevation in VDR expression was observed in coronary artery segments of vitamin-D-deficient female rats [43]. Vitamin-D-dependent and -independent actions of VDR have been described, and vice versa, VDR-dependent and -independent vitamin D actions have been distinguished [49].

The beneficial effects of vitamin D supplementation on cardiovascular health have not been proved in large randomized, controlled, and follow-up clinical studies (e.g., the 'VITAL', 'DO-HEALTH', and 'VIDA' studies) [50-52]. However, it is important to highlight that these trials involved not only vitamin-D-deficient and -insufficient participants 
$(25(\mathrm{OH}) \mathrm{D}<30 \mathrm{ng} / \mathrm{mL}$ or $<75 \mathrm{nmol} / \mathrm{L})$, but also vitamin-D-sufficient $(25(\mathrm{OH}) \mathrm{D}>30 \mathrm{ng} / \mathrm{mL}$ or $>75 \mathrm{nmol} / \mathrm{L}$ ) participants. Thus, it is necessary to investigate adequately the effects of vitamin D supplementation in only vitamin-D-deficient and in vitamin-D-insufficient target groups in both sexes and different ages (infants, children, adolescents, adults, and the elderly).

Despite the controversies, vitamin D deficiency can be considered an independent cardiovascular risk factor [2]. A population-based study and meta-analysis of several studies showed that increased risk for myocardial infarction, ischemic heart disease, and early death are associated with decreasing 25(OH)D level [53]. Vitamin-D-insufficient middle-aged men had significantly lower coronary flow reserve than a vitamin-D-sufficient group [54]. Combined testosterone and vitamin D deficiencies in a coronary angiographyreferred study population of older men showed a significant association with all-cause, cardiovascular, and non-cardiovascular mortality compared to men without any hormone deficiency [55].

In summary, according to our results, vitamin-D-deficient male coronary arteries showed damaged pharmacological reactivity to $\mathrm{TXA}_{2}$ and different sexual steroid hormones $(\mathrm{E} 2, \mathrm{~T})$. The most important adenosine vasodilator pathway in coronary arteries was still intact. Insufficient vasoconstrictor capacity occurred in decreased TP receptor expression, while the vasodilator alterations were mainly functional. The possible background of these differences may be the involvement of other, non-genomic endothelium-independent vasodilator pathways of sexual steroids. In case of a decrease in both vasoconstrictor and vasodilator responses, the adaptational range of the intramural coronaries is narrowed, which causes inadequate coronary perfusion and deteriorates the heart's blood supply.

\section{Conclusions}

To our knowledge, this is the first experiment that has investigated the vascular reactivity of small intramural coronary artery segments from vitamin-D-deficient male rats in response to thromboxane, 17- $\beta$-estradiol, testosterone, adenosine, and insulin. We found significant alterations in thromboxane vasoconstriction and estrogen and androgen sexual-steroid-induced relaxations, which have already been shown partially on the level of receptor expression. These alterations narrow the pharmacological adaptational range of these small vessels, which leads to the deterioration of the heart's perfusion. In addition to chronic hypoperfusion, their current adaptation abilities also worsen. The described changes might contribute to the increased cardiovascular risk in vitamin D deficiency.

Author Contributions: Conceptualization, G.M. and S.V.; Data curation, R.E.S. and É.P.; Formal analysis, Z.F. and R.E.S.; Funding acquisition, G.L.N. and S.V.; Investigation, Z.F., R.E.S., É.P., L.H., A.M.-K., R.B., A.M. and A.H.; Methodology, L.H., E.M.H., G.L.N. and S.V.; Project administration, R.E.S., É.P., L.H. and S.V.; Resources, E.M.H., Z.B., G.L.N. and S.V.; Software, R.E.S. and E.M.H.; Supervision, E.M.H., G.L.N. and S.V.; Validation, E.M.H., G.L.N. and S.V.; Visualization, R.E.S.; Writing—original draft, Z.F., R.E.S., G.M. and S.V.; Writing—review and editing, Z.F., R.E.S., É.P., E.M.H., R.B., G.L.N., G.M. and S.V. All authors have read and agreed to the published version of the manuscript.

Funding: This research was funded by the Semmelweis Science and Innovation Fund (STIA-KF-17 for S.V.), grants from the Hungarian Hypertension Society (2015/01, for S.V., G.L.N.), and the Dean of the Medical Faculty, Semmelweis University (2016/8, for S.V., G.L.N.).

Institutional Review Board Statement: The study was conducted according to the Guide for the Care and Use of Laboratory Animals published by the US National Institutes of Health (8th edition, 2011) and the EU-conforming Hungarian Law on Animal Care (XXVIII/1998). The Institutional Animal Care and Use Committee of Semmelweis University approved the study protocol (PEI/001/8202/2015).

Informed Consent Statement: Not applicable.

Acknowledgments: We thank Ildikó Murányi for the technical support. We also thank Ilona Sziva for critically reading the manuscript. 
Conflicts of Interest: The authors declare no conflict of interest.

\section{References}

1. Bouillon, R. Vitamin D and cardiovascular disorders. Osteoporos. Int. 2019, 30, 2167-2181. [CrossRef] [PubMed]

2. Kienreich, K.; Tomaschitz, A.; Verheyen, N.; Pieber, T.; Gaksch, M.; Grubler, M.R.; Pilz, S. Vitamin D and cardiovascular disease. Nutrients 2013, 5, 3005-3021. [CrossRef] [PubMed]

3. Gholami, F.; Moradi, G.; Zareei, B.; Rasouli, M.A.; Nikkhoo, B.; Roshani, D.; Ghaderi, E. The association between circulating 25-hydroxyvitamin D and cardiovascular diseases: A meta-analysis of prospective cohort studies. BMC Cardiovasc. Disord. 2019, 19, 248. [CrossRef] [PubMed]

4. Pludowski, P.; Karczmarewicz, E.; Bayer, M.; Carter, G.; Chlebna-Sokol, D.; Czech-Kowalska, J.; Debski, R.; Decsi, T.; Dobrzanska, A.; Franek, E.; et al. Practical guidelines for the supplementation of vitamin D and the treatment of deficits in Central Europerecommended vitamin D intakes in the general population and groups at risk of vitamin D deficiency. Endokrynol. Pol. 2013, 64, 319-327. [CrossRef]

5. Giustina, A.; Bouillon, R.; Binkley, N.; Sempos, C.; Adler, R.A.; Bollerslev, J.; Dawson-Hughes, B.; Ebeling, P.R.; Feldman, D.; Heijboer, A.; et al. Controversies in Vitamin D: A Statement From the Third International Conference. JBMR Plus 2020, 4 , e10417. [CrossRef]

6. Hii, C.S.; Ferrante, A. The Non-Genomic Actions of Vitamin D. Nutrients 2016, 8, 135. [CrossRef]

7. Pike, J.W.; Christakos, S. Biology and Mechanisms of Action of the Vitamin D Hormone. Endocrinol. Metab. Clin. N. Am. 2017, 46, 815-843. [CrossRef]

8. Mozos, I.; Marginean, O. Links between Vitamin D Deficiency and Cardiovascular Diseases. Biomed. Res. Int. 2015, 2015 , 109275. [CrossRef]

9. Dawber, T.R.; Kannel, W.B.; Revotskie, N.; Stokes, J., 3rd; Kagan, A.; Gordon, T. Some factors associated with the development of coronary heart disease: Six years' follow-up experience in the Framingham study. Am. J. Public Health Nations Health 1959, 49, 1349-1356. [CrossRef]

10. Dawber, T.R.; Moore, F.E.; Mann, G.V. Coronary heart disease in the Framingham study. Am. J. Public Health Nations Health 1957, 47, 4-24. [CrossRef]

11. Kannel, W.B.; Dawber, T.R.; Kagan, A.; Revotskie, N.; Stokes, J., 3rd. Factors of risk in the development of coronary heart disease-Six year follow-up experience. The Framingham Study. Ann. Intern. Med. 1961, 55, 33-50. [CrossRef]

12. Wong, N.D.; Levy, D. Legacy of the framingham heart study: Rationale, design, initial findings, and implications. Glob. Heart 2013, 8, 3-9. [CrossRef]

13. Madan, N.; Gajo, E.; Sanghani, R.M.; Volgman, A.S. Sex-Based Considerations in the Evaluation of Chest Pain and Management of Obstructive Coronary Artery Disease. Curr. Atheroscler. Rep. 2020, 22, 39. [CrossRef]

14. Kristensen, S.D.; Husted, S.E.; Nielsen, H.K.; Ravn, H.B.; Vissinger, H. Interaction between thrombocytes and blood vessel wall-Significance for acute ischemic coronary syndromes. Ugeskr. Laeger 1995, 157, 2295-2298.

15. Ellinsworth, D.C.; Shukla, N.; Fleming, I.; Jeremy, J.Y. Interactions between thromboxane A(2), thromboxane/prostaglandin (TP) receptors, and endothelium-derived hyperpolarization. Cardiovasc. Res. 2014, 102, 9-16. [CrossRef]

16. Braune, S.; Kupper, J.H.; Jung, F. Effect of Prostanoids on Human Platelet Function: An Overview. Int. J. Mol. Sci. 2020, 21, 9020. [CrossRef]

17. Aryan, L.; Younessi, D.; Zargari, M.; Banerjee, S.; Agopian, J.; Rahman, S.; Borna, R.; Ruffenach, G.; Umar, S.; Eghbali, M. The Role of Estrogen Receptors in Cardiovascular Disease. Int. J. Mol. Sci. 2020, 21, 4314. [CrossRef]

18. Lorigo, M.; Mariana, M.; Oliveira, N.; Lemos, M.C.; Cairrao, E. Vascular Pathways of Testosterone: Clinical Implications. J. Cardiovasc. Transl. Res. 2020, 13, 55-72. [CrossRef]

19. Fuentes, N.; Silveyra, P. Estrogen receptor signaling mechanisms. Adv. Protein Chem. Struct. Biol. 2019, 116, 135-170. [CrossRef]

20. Guivarc'h, E.; Buscato, M.; Guihot, A.L.; Favre, J.; Vessieres, E.; Grimaud, L.; Wakim, J.; Melhem, N.J.; Zahreddine, R.; Adlanmerini, M.; et al. Predominant Role of Nuclear Versus Membrane Estrogen Receptor alpha in Arterial Protection: Implications for Estrogen Receptor alpha Modulation in Cardiovascular Prevention/Safety. J. Am. Heart Assoc. 2018, 7, e008950. [CrossRef]

21. Lucas-Herald, A.K.; Alves-Lopes, R.; Montezano, A.C.; Ahmed, S.F.; Touyz, R.M. Genomic and non-genomic effects of androgens in the cardiovascular system: Clinical implications. Clin. Sci. 2017, 131, 1405-1418. [CrossRef]

22. Salzano, A.; Demelo-Rodriguez, P.; Marra, A.M.; Proietti, M. A Focused Review of Gender Differences in Antithrombotic Therapy. Curr. Med. Chem. 2017, 24, 2576-2588. [CrossRef]

23. Pal, E.; Hadjadj, L.; Fontanyi, Z.; Monori-Kiss, A.; Mezei, Z.; Lippai, N.; Magyar, A.; Heinzlmann, A.; Karvaly, G.; Monos, E.; et al. Vitamin D deficiency causes inward hypertrophic remodeling and alters vascular reactivity of rat cerebral arterioles. PLoS ONE 2018, 13, e0192480. [CrossRef]

24. Nadasy, G.L.; Szekeres, M.; Dezsi, L.; Varbiro, S.; Szekacs, B.; Monos, E. Preparation of intramural small coronary artery and arteriole segments and resistance artery networks from the rat heart for microarteriography and for in situ perfusion video mapping. Microvasc. Res. 2001, 61, 282-286. [CrossRef]

25. Sziva, R.E.; Fontanyi, Z.; Pal, E.; Hadjadj, L.; Monori-Kiss, A.; Horvath, E.M.; Benko, R.; Magyar, A.; Heinzlmann, A.; Benyo, Z.; et al. Vitamin D Deficiency Induces Elevated Oxidative and Biomechanical Damage in Coronary Arterioles in Male Rats. Antioxidants 2020, 9, 997. [CrossRef] 
26. Varbiro, S.; Matrai, M.; Szekeres, M.; Nadasy, G.L.; Szaky, E.; Mericli, M.; Banhidy, F.; Monos, E.; Szekacs, B. Intramural coronary artery constrictor reactivity to thromboxane is higher in male than in female rats. Gynecol. Endocrinol. 2006, 22, 44-47. [CrossRef]

27. Moreno, J.; Krishnan, A.V.; Swami, S.; Nonn, L.; Peehl, D.M.; Feldman, D. Regulation of prostaglandin metabolism by calcitriol attenuates growth stimulation in prostate cancer cells. Cancer Res. 2005, 65, 7917-7925. [CrossRef]

28. Moreno, J.; Krishnan, A.V.; Peehl, D.M.; Feldman, D. Mechanisms of vitamin D-mediated growth inhibition in prostate cancer cells: Inhibition of the prostaglandin pathway. Anticancer Res. 2006, 26, 2525-2530.

29. Feldman, D.; Krishnan, A.; Moreno, J.; Swami, S.; Peehl, D.M.; Srinivas, S. Vitamin D inhibition of the prostaglandin pathway as therapy for prostate cancer. Nutr. Rev. 2007, 65, S113-S115. [CrossRef]

30. Horiuchi, H.; Nagata, I.; Komoriya, K. Protective effect of vitamin D3 analogues on endotoxin shock in mice. Agents Actions 1991, 33, 343-348. [CrossRef]

31. Wong, M.S.; Delansorne, R.; Man, R.Y.; Svenningsen, P.; Vanhoutte, P.M. Chronic treatment with vitamin D lowers arterial blood pressure and reduces endothelium-dependent contractions in the aorta of the spontaneously hypertensive rat. Am. J. Physiol. Heart Circ. Physiol. 2010, 299, H1226-H1234. [CrossRef] [PubMed]

32. Wong, M.S.; Delansorne, R.; Man, R.Y.; Vanhoutte, P.M. Vitamin D derivatives acutely reduce endothelium-dependent contractions in the aorta of the spontaneously hypertensive rat. Am. J. Physiol. Heart Circ. Physiol. 2008, 295, H289-H296. [CrossRef] [PubMed]

33. Feng, J.; Liu, Y.; Chu, L.M.; Clements, R.T.; Khabbaz, K.R.; Robich, M.P.; Bianchi, C.; Sellke, F.W. Thromboxane-induced contractile response of human coronary arterioles is diminished after cardioplegic arrest. Ann. Thorac. Surg. 2011, 92, 829-836. [CrossRef] [PubMed]

34. Nandi, A.A.; Wadhwani, N.S.; Joshi, S.R. Maternal vitamin D deficiency increases the thromboxane/prostacyclin ratio through alterations in the one-carbon cycle in Wistar rats. Biofactors 2019, 45, 548-555. [CrossRef]

35. Nandi, A.; Wadhwani, N.; Joshi, S.R. Vitamin D deficiency influences fatty acid metabolism. Prostaglandins Leukot. Essent. Fatty Acids 2019, 140, 57-63. [CrossRef]

36. Hadjadj, L.; Monori-Kiss, A.; Horvath, E.M.; Heinzlmann, A.; Magyar, A.; Sziva, R.E.; Miklos, Z.; Pal, E.; Gal, J.; Szabo, I.; et al. Geometric, elastic and contractile-relaxation changes in coronary arterioles induced by Vitamin D deficiency in normal and hyperandrogenic female rats. Microvasc. Res. 2019, 122, 78-84. [CrossRef]

37. Pugh, P.J.; Jones, R.D.; Jones, T.H.; Channer, K.S. Intrinsic responses of rat coronary arteries in vitro: Influence of testosterone, calcium, and effective transmural pressure. Endocrine 2002, 19, 155-161. [CrossRef]

38. Pal, E.; Hadjadj, L.; Fontanyi, Z.; Monori-Kiss, A.; Lippai, N.; Horvath, E.M.; Magyar, A.; Horvath, E.; Monos, E.; Nadasy, G.L.; et al. Gender, hyperandrogenism and vitamin D deficiency related functional and morphological alterations of rat cerebral arteries. PLoS ONE 2019, 14, e0216951. [CrossRef]

39. Santos, R.L.; Abreu, G.R.; Bissoli, N.S.; Moyses, M.R. Endothelial mediators of 17 beta-estradiol-induced coronary vasodilation in the isolated rat heart. Braz. J. Med. Biol. Res. 2004, 37, 569-575. [CrossRef]

40. Santos, R.L.; Marin, E.B.; Goncalves, W.L.; Bissoli, N.S.; Abreu, G.R.; Moyses, M.R. Sex differences in the coronary vasodilation induced by 17 beta-oestradiol in the isolated perfused heart from spontaneously hypertensive rats. Acta Physiol. 2010, 200, 203-210. [CrossRef]

41. Santos, R.L.; Lima, J.T.; Rouver, W.N.; Moyses, M.R. Deficiency of sex hormones does not affect 17-ss-estradiol-induced coronary vasodilation in the isolated rat heart. Braz. J. Med. Biol. Res. 2016, 49, e5058. [CrossRef]

42. Levy, A.S.; Chung, J.C.; Kroetsch, J.T.; Rush, J.W. Nitric oxide and coronary vascular endothelium adaptations in hypertension. Vasc. Health Risk Manag. 2009, 5, 1075-1087. [CrossRef]

43. Hadjadj, L.; Varbiro, S.; Horvath, E.M.; Monori-Kiss, A.; Pal, E.; Karvaly, G.B.; Heinzlmann, A.; Magyar, A.; Szabo, I.; Sziva, R.E.; et al. Insulin resistance in an animal model of polycystic ovary disease is aggravated by vitamin D deficiency: Vascular consequences. Diabetes Vasc. Dis. Res. 2018, 15, 294-301. [CrossRef]

44. Lajtai, K.; Tarszabó, R.; Bányai, B.; Péterffy, B.; Gerszi, D.; Ruisanchez, É.; Sziva, R.E.; Korsós-Novák, Á.; Benkő, R.; Hadjadj, L.; et al. Effect of Vitamin D Status on Vascular Function of the Aorta in a Rat Model of PCOS. Oxid. Med. Cell. Longev. 2021, 2021, 8865979. [CrossRef]

45. Bouillon, R.; Marcocci, C.; Carmeliet, G.; Bikle, D.; White, J.H.; Dawson-Hughes, B.; Lips, P.; Munns, C.F.; Lazaretti-Castro, M.; Giustina, A.; et al. Skeletal and Extraskeletal Actions of Vitamin D: Current Evidence and Outstanding Questions. Endocr. Rev. 2019, 40, 1109-1151. [CrossRef]

46. Zhang, J.; McCullough, P.A.; Tecson, K.M. Vitamin D deficiency in association with endothelial dysfunction: Implications for patients with COVID-19. Rev. Cardiovasc. Med. 2020, 21, 339-344. [CrossRef]

47. de la Guia-Galipienso, F.; Martinez-Ferran, M.; Vallecillo, N.; Lavie, C.J.; Sanchis-Gomar, F.; Pareja-Galeano, H. Vitamin D and cardiovascular health. Clin. Nutr. 2020. [CrossRef]

48. Maggio, M.; De Vita, F.; Lauretani, F.; Ceda, G.P.; Volpi, E.; Giallauria, F.; De Cicco, G.; Cattabiani, C.; Melhus, H.; Michaelsson, K.; et al. Vitamin D and endothelial vasodilation in older individuals: Data from the PIVUS study. J. Clin. Endocrinol. Metab. 2014, 99, 3382-3389. [CrossRef]

49. Dusso, A.S.; Brown, A.J.; Slatopolsky, E. Vitamin D. Am. J. Physiol. Ren. Physiol. 2005, 289, F8-F28. [CrossRef]

50. Bischoff-Ferrari, H.A.; Vellas, B.; Rizzoli, R.; Kressig, R.W.; da Silva, J.A.P.; Blauth, M.; Felson, D.T.; McCloskey, E.V.; Watzl, B.; Hofbauer, L.C.; et al. Effect of Vitamin D Supplementation, Omega-3 Fatty Acid Supplementation, or a Strength-Training Exercise 
Program on Clinical Outcomes in Older Adults: The DO-HEALTH Randomized Clinical Trial. JAMA 2020, 324, $1855-1868$. [CrossRef]

51. Tice, J.A.; Halalau, A.; Burke, H. Vitamin D Does Not Prevent Cancer or Cardiovascular Disease: The VITAL Trial: Manson, J.E.; Cook, N.R.; Lee, I.M.; Christen, W.; Bassuk, S.S.; Mora, S.; Gibson, H.; Gordon, D.; Copeland, T.; D'Agostino, D.; et al. Vitamin D Supplements and Prevention of Cancer and Cardiovascular Disease. N. Engl. J. Med. 2019, 380, 33-44. [CrossRef]

52. Scragg, R. The Vitamin D Assessment (ViDA) study—Design and main findings. J. Steroid Biochem. Mol. Biol. 2020, 198, 105562. [CrossRef]

53. Brondum-Jacobsen, P.; Benn, M.; Jensen, G.B.; Nordestgaard, B.G. 25-hydroxyvitamin d levels and risk of ischemic heart disease, myocardial infarction, and early death: Population-based study and meta-analyses of 18 and 17 studies. Arter. Thromb. Vasc. Biol. 2012, 32, 2794-2802. [CrossRef]

54. Karohl, C.; Vaccarino, V.; Veledar, E.; Goldberg, J.; Tangpricha, V.; Bellasi, A.; Raggi, P. Vitamin D status and coronary flow reserve measured by positron emission tomography: A co-twin control study. J. Clin. Endocrinol. Metab. 2013, 98, 389-397. [CrossRef]

55. Lerchbaum, E.; Pilz, S.; Boehm, B.O.; Grammer, T.B.; Obermayer-Pietsch, B.; Marz, W. Combination of low free testosterone and low vitamin D predicts mortality in older men referred for coronary angiography. Clin. Endocrinol. 2012, 77, 475-483. [CrossRef] 